\title{
Characterization of Fusarium graminearum isolates recovered from wheat samples from Argentina by Fourier transform infrared spectroscopy: Phenotypic diversity and detection of specific markers of aggressiveness
}

\author{
Cecilia B. Fígoli a ${ }^{\text {, Rodrigo Rojo }}{ }^{\mathrm{b}}$, Laura A. Gasoni ${ }^{\mathrm{b}}$, Gisele Kikot ${ }^{\mathrm{c}}$, Mariana Leguizamón ${ }^{\text {a }}$, Raúl R. Gamba ${ }^{\mathrm{d}}$, \\ Alejandra Bosch ${ }^{\mathrm{a}}$, Teresa M. Alconada ${ }^{\mathrm{c}, *}$ \\ a Laboratorio de Bioespectroscopía, CINDEFI-UNLP-CONICET-CCT La Plata, Facultad de Ciencias Exactas, Universidad Nacional de La Plata, calle 47 y 115 , CP: B1900ASH La Plata, Argentina \\ ${ }^{\mathrm{b}}$ Instituto de Microbiología y Zoología Agrícola (IMYZA), Instituto Nacional de Tecnología Agropecuaria (INTA), Los Reseros y Las Cabañas s/n, B1712WAA Hurlingham, Argentina

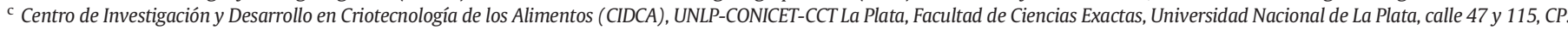 \\ B1900AS La Plata, Argentina

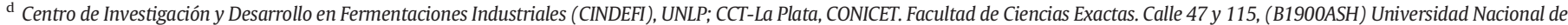 \\ La Plata, Argentina
}

\section{A R T I C L E I N F O}

\section{Article history:}

Received 16 July 2016

Received in revised form 12 December 2016

Accepted 25 December 2016

Available online 28 December 2016

\section{Keywords:}

Fusarium graminearum

FTIR spectroscopy

Phenotypic diversity

Aggressiveness

\begin{abstract}
A B S T R A C T
Fusarium graminearum is the primary causal agent of Fusarium head blight of wheat in Argentina. This disease affects crop yields and grain quality also reducing the wheat end-use, and causing mycotoxin contamination. The aim of this work was to analyze the phenotypic characteristics associated with phenotypic diversity and aggressiveness of 34 F. graminearum sensu stricto isolates recovered from Argentinean fields in the 2008 growing season using the Fourier Transform Infrared (FTIR) dried film technology. We applied this technique also to search for spectral specific markers associated with aggressiveness. The combination of FTIR technology with hierarchical cluster analysis allowed us to determine that this population constitutes a highly diverse and heterogeneous group of fungi with significant phenotypic variance. Still, when the spectral features of a set of these isolates were compared against their aggressiveness, as measured by disease severity, thousand grains weight, and relative yield reduction, we found that the more aggressive isolates were richer in lipid content. Therefore, we could define several spectroscopic markers $(>\mathrm{C}-\mathrm{H}$ stretching modes in the 3000-2800 window, $>\mathrm{C}=\mathrm{O}$ and $-\mathrm{C}-\mathrm{O}$ vibrational modes of esters at $1765-1707 \mathrm{~cm}^{-1}$ and $1474-900 \mathrm{~cm}^{-1}$, respectively), mostly assigned to lipid content that could be associated with F. graminearum aggressiveness. All together, by the application of FTIR techniques and simple multivariate analyses, it was possible to gain significant insights into the phenotypic characterization of $F$. graminearum local isolates, and to establish the existence of a direct relationship between lipid content and fungal aggressiveness. Considering that lipids have a major role as mediators in the interaction between plants and fungi our results could represent an attractive outcome in the study of Fusarium pathogenesis.
\end{abstract}

() 2017 Elsevier B.V. All rights reserved.

\section{Introduction}

Fusarium head blight (FHB) is a major devastating fungi disease of wheat worldwide. It causes a decrease in grain quality, weight, carbohydrate and protein content; thus affects the yield and quality of grain production. It can also lead to severe health problems in consumers due to the production of associated mycotoxins (Matny, 2015). FHB is caused by different species within Fusarium graminearum species complex (FGSC), F. graminearum sensu stricto (teleomorph Gibberella zeae) being the main pathogen reported in South America (Alvarez et al.,

\footnotetext{
* Corresponding author.

E-mail address: alconada@biotec.quimica.unlp.edu.ar (T.M. Alconada).
}

2011; Castañares et al., 2014; Ramírez et al., 2007). Its incidence has increased over the past several decades worldwide (Goswami and Kistler, 2004; Ortega et al., 2016). The International Maize and Wheat Improvement Centre has identified this disease as the major factor limiting wheat production (Xu, 2003).

Aggressiveness of a fungal pathogen is measured by the quantity of disease induced by a pathogenic isolate on a susceptible host. Aggressiveness levels particularly among isolates of $F$. graminearum, were previously studied by point inoculating spikes of field grown wheat evaluating the disease severity during the 3-week-period after inoculation, among other methods (Malbrán et al., 2012; Talas et al., 2012). Studies performed with isolates within FGSC showed that the variability in aggressiveness levels was not correlated with the species, but it was 
strain dependant (Goswami and Kistler, 2004; Malbrán et al., 2014). The mycotoxins most associated with members of the FGSC are deoxynivalenol (DON) and nivalenol (NIV), which have several adverse effects on animal and human health (Pestka, 2007). In South America, and particularly in Argentina, the DON chemotype seems to be predominant in the wheat-cropping area (Astolfi et al., 2012; Castañares et al., 2014; Malbrán et al., 2014; Umpiérrez-Failache et al., 2013). Latin American countries in general and mainly Brazil and Argentina are important wheat producers, Argentina being among the major wheat exporters worldwide (Bolsa de Comercio de Rosario, 2014; Reynoso et al., 2011). At least $20 \mathrm{FHB}$ epidemics of wheat were registered in the last 50 years in Argentina with variable intensity, which produced alterations in the harvested wheat quality (Kikot et al., 2011; Malbrán et al., 2014).

Different phenotypic and molecular approaches have been applied for the characterization of $F$. graminearum populations recovered from different agricultural regions in the world (Alvarez et al., 2011; Carter et al., 2002; Cumagun and Miedaner, 2004; Goswami and Kistler, 2004; Leslie et al., 2007; Malbrán et al., 2012, 2014; Ortega et al., 2016; Ramírez et al., 2007; Somma et al., 2014; Wang et al., 2011). Regarding their phenotypic features, the studies were focused mainly on the analysis of aggressiveness and expression of virulence factors. They ranged from visual evaluation of parameters of disease severity to the interpretation of the role of enzyme activities and mycotoxins in the infection process, including the study of the genes that regulate these mechanisms (Cumagun and Miedaner, 2004; Malbrán et al., 2012, 2014). However, an in depth study on phenotypic heterogeneity of $F$. graminearum local population and aggressiveness has not been accomplished, so far.

Fourier transform infrared spectroscopy (FTIR) provides a spectroscopic fingerprint of the total biochemical and structural composition of the material under study. In the last decades, it has widely been applied for the detection, identification and phenotypic characterization of bacteria, yeast and filamentous fungi (Lecellier et al., 2015; Mariey et al., 2001). Once the cultivation conditions, sampling and measurement parameters are well standardized this physicochemical approach enables the creation of reference libraries which can be applied for identification of unknown microorganisms. FTIR spectroscopy technology has been extensively used in food microbiology and agriculture (Bosch et al., 2006; Mariey et al., 2001; Wenning et al., 2014). Nevertheless, it has been only occasionally applied in the study of fungal contamination of cereals or agricultural commodities (Hossain and Goto, 2014; Salman et al., 2011), or in the discrimination or characterization of different species of Fusarium genus (Levasseur et al., 2010; Nie et al., 2007b; Salman et al., 2011).

The aim of this work was to use FTIR spectroscopy to evaluate the phenotypic diversity of a population of $34 \mathrm{~F}$. graminearum sensu stricto isolates recovered from Argentine fields in the 2008 growing season, and to analyze a possible association between phenotypic heterogeneity and aggressiveness. Furthermore, we aimed to apply this technology to search for spectral specific markers associated with aggressiveness.

\section{Materials and methods}

\subsection{Biological material}

Twenty wheat samples obtained during the 2008 wheat growing season were provided by the Argentine experimental stations belonging to Instituto Nacional de Tecnología Agropecuaria (INTA) from Paraná ( $31^{\circ} 44^{\prime} 40^{\prime \prime} \mathrm{S} 60^{\circ} 31^{\prime} 03^{\prime \prime} \mathrm{O}$ ), Pergamino ( $33^{\circ} 53^{\prime} 00^{\prime \prime} \mathrm{S} 60^{\circ} 34^{\prime} 00^{\prime \prime} \mathrm{O}$ ) and Oliveros ( $32^{\circ} 34^{\prime} 00^{\prime \prime} \mathrm{S} 60^{\circ} 51^{\prime} 00^{\prime \prime} \mathrm{O}$ ) locations situated at Entre Ríos, Buenos Aires and Santa Fe provinces, respectively. The fields were managed by conventional tillage operations according to standard production practices.

\subsection{Isolation of fusarium graminearum}

For F. graminearum isolation, 200 grains of wheat from each sample were surface-sterilized applying $10 \% \mathrm{v} / \mathrm{v}$ sodium hypochlorite solution for $10 \mathrm{~min}$, and washing thoroughly with sterile distilled water three times. Next, they were plated onto Petri dishes containing wet filter paper, and incubated in darkness at $25^{\circ} \mathrm{C}$ for 7 days. Grains that showed fungal growth were transferred to Potato Dextrose Agar (PDA) medium. The mycelial biomass recovered was subcultured on synthetic nutrient agar (SNA) medium for 15 days and the conidial suspension obtained was transferred to water agar (WA) medium for $16 \mathrm{~h}$. Single macroconidial isolates of Fusarium spp. were characterized by their growth rate on PDA medium, and by visually assessment of pigmentation and aerial mycelium aspects (Nelson et al., 1994). For microscopic characterization, the isolates were grown on CLA. Microscopic observations were carried out at $\times 100$ magnification (Leica 2500, Germany). Macroconidia morphology, presence/absence of microconidia and perithecium production was determined. The identification was carried out by means of the different taxonomic keys previously described (Gerlach and Nirenberg, 1982; Burgess et al., 1994; Leslie and Summerell, 2006).

\subsection{Molecular identification}

Total genomic DNA from presumptive $F$. graminearum isolates was extracted using the cetyltrimethylammonium bromide (CTAB) method (Stenglein and Balatti, 2006), and DNA concentrations were calculated using a NanoDrop 2000 UV-vis spectrophotometer (Thermo Fisher Scientific, Waltham, MA, USA). A PCR assay was performed using Fg16F and Fg16R primers as described by Nicholson et al. (1998). Although these primers are not completely specific to F. graminearum s.s., they give products of different sizes depending on the species: Fusarium graminearum s.s. gives a product of about $400 \mathrm{bp}$, F. asiaticum, NRRL 13818 strain, used as control, yields a PCR product of $550 \mathrm{bp} ; \mathrm{F}$. meridionale, NRRL 28436 strain, yields a product of $500 \mathrm{bp}$; and no amplification was expected for $F$. boothii, NRRL 26916 strain (Castañares et al., 2014). The species used as controls were selected according to Fusarium species incidence in South America (van der Lee et al., 2015). Sixty isolates were identified as Fusarium graminearum s.s. from which 34 were selected for this investigation. Isolates were named from 1 to 34 as follows: isolates number 1 to 16 belonged to Oliveros, Santa Fe Province, isolates number 17 to 26 to Pergamino, Buenos Aires, and isolates number 27 to 34 to Paraná, Entre Ríos Province.

\subsection{Fourier transform infrared spectroscopy (FTIR)}

\subsubsection{Sample preparation}

A stock culture of each isolate was grown on SNA. After 10 days of incubation at $27^{\circ} \mathrm{C}$, agar plugs containing the fungus were transferred to a $500 \mathrm{~mL}$-flask with $10 \%$ potato dextrose broth (PDB, DIFCO, USA) and grown at $27^{\circ} \mathrm{C}$ with continuous shaking at $160 \mathrm{rpm}$ for 3 days. Subsequently, three samples of $5 \mathrm{~mL}$ each were withdrawn and centrifuged at $2000 \mathrm{rpm}$ for $5 \mathrm{~min}$. Pellets were washed 4 times with distilled water, suspended in $1 \mathrm{~mL}$, and homogenized using water bath sonication at room temperature, for $30 \mathrm{~min}$, at 200 watt (Cleanson sonicator, Argentina). Aliquots of $100 \mu \mathrm{L}$ of the fungal suspension were transferred to ZnSe optical plates (13 mm diameter, Korth Kristalle GMBH, Germany) and dried under vacuum to obtain transparent films (Helm and Naumann, 1995; Naumann, 2000).

\subsubsection{Experimental set up and spectral acquisition}

For a stock culture of each of the 34 Fusarium graminearum s.s. isolates here studied, three fungal pellets were recovered from the PDB cultures as indicated in sample preparation section in order to evaluate three technical replicates. Besides, three independent runs were performed for each isolate over a 6 -month period to account for possible biological sources of variance ( 3 biological replicates). Then, 306 samples 
were prepared for spectral acquisition (three technical replicates obtained from three biological replicates for 34 isolates).

FTIR absorption/transmission (A/T) spectra in the 4000 to $600 \mathrm{~cm}^{-1}$ range were acquired with a FTIR spectrometer (Spectrum One, PerkinElmer, USA) with $6 \mathrm{~cm}^{-1}$ spectral resolution and 64 scan co-additions. To avoid interference with spectral water vapour bands, spectra were measured under a continuous purge of dried air.

\subsubsection{Spectral data pre-processing}

Before data analysis, a quality test (QT) was performed on the whole set of 306 spectra, using OPUS software (Helm and Naumann, 1995; Naumann, 2000). This test included i) a check for absorbance in the Amide I region (1700-1600 $\mathrm{cm}^{-1}$ ), ii) for the noise signal (calculated from the first derivative between 2100 and $2000 \mathrm{~cm}^{-1}$ ) and iii) for the water vapour content (determined from the first derivatives between 1847 and $1837 \mathrm{~cm}^{-1}$ ). All spectra that passed the QT were subject to a pre-processing procedure: Firstly, the three technical replicates were averaged (for some samples only two technical replicates were included due to few spectra that did not pass the QT analysis). Hence, the number of spectra for data analysis was reduced to 102. Then, second derivatives were calculated on these average spectra using the Savitzky-Golay algorithm with 9-point smoothing to increase the number of discriminative features present in the spectra and to minimize problems with baseline shifts. Finally, to avoid interference from biomass variations among the different samples, the second derivatives were vector normalized in the full range (Helm and Naumann, 1995; Naumann, 2000; Bosch et al., 2008). OPUS software (versions 4.2; and 7.0 Bruker Optics GmbH, Ettlingen, Germany) was used for spectral pre-processing.

\subsubsection{Data analysis}

2.4.4.1. Analysis of the FTIR phenotype variability. In order to determinate the variability among the FTIR phenotypes obtained for each isolate we calculated the variability among biological replicates as previously described by Rebuffo and co-workers for Listeria isolate discrimination (Rebuffo et al., 2006). Briefly, the variability among biological replicates of every isolate was calculated for three spectral regions: 3000 $2800 \mathrm{~cm}^{-1}, 1800-1500 \mathrm{~cm}^{-1}$ and $1200-700 \mathrm{~cm}^{-1}$, as the average plus or minus 2 standard deviations of the so-called spectral distance (D), which is a measure of dissimilarity. $D$ is equal to $(1-r) \times 1000$ and $r$ is Pearson's correlation coefficient (Kohler et al., 2015; Bosch et al., 2008; Naumann, 2000; Helm and Naumann, 1995).

2.4.4.2. Hierarchical cluster analysis (HCA). A non-supervised discriminant analysis among the FTIR phenotypes of the 34 isolates was performed by HCA. For this purpose, the second-derivative vector normalized of the 102 average spectra (see Spectral data preprocessing section) was used as input data. Scaling to first range was selected for the calculation of distances among spectra in the spectral windows: $3000-2800,1700-1500,1550-1200$ and $1250-650 \mathrm{~cm}^{-1}$, and Ward's algorithm was used to construct the dendrogram (Helm et al., 1991; Naumann, 2000).

2.4.4.3. Evaluation of lipid content in F. graminearum isolates. Semi-quantitative parameter of lipid content was determined calculating the band areas at the two main picks assigned to lipids: $2853 \mathrm{~cm}^{-1}$ (2865$2835 \mathrm{~cm}^{-1}$ region, due to $\mathrm{C}-\mathrm{H}$ stretching in methylene $>\mathrm{CH}_{2}$ ) and $1742 \mathrm{~cm}^{-1}$ (1763-1696 $\mathrm{cm}^{-1}$ region, due to $>C=0$ stretching vibration of ester groups) in the vector normalized spectra for the nine isolates in which the aggressiveness was analyzed. Statistical analysis was performed by a mixed model analysis of variance (ANOVA; $p=$ 0.05, InfoStat version 2015).

2.4.4.4. Principal component analysis (PCA). A PCA was applied using second derivatives vector normalized spectra in the wavenumber regions associated to lipids absorbance (3000-2800, 1750-1740, 1470-1455 and $1200-1100 \mathrm{~cm}^{-1}$ ) (Naumann, 2000). The nine isolates used for the aggressiveness assays were included in the PCA study and a Scoreplot was obtained.

All the FTIR data analysis was performed by means of OPUS software, versions 4 and 7.0 (Bruker Optics GmbH, Ettlingen, Germany).

\subsection{Greenhouse aggressiveness test}

Aggressiveness was assessed in $9 \mathrm{~F}$. graminearum isolates by singlefloret spore-inoculation (Engle et al., 2003) on an Argentinean susceptible wheat cultivar (Buck Halcon). These isolates were selected for their different FTIR phenotype (belonging to different clusters), and for their sporulation extent (isolates with a sporulation level sufficient to permit a successful infection were chosen). The fungal inoculum used in this assay was obtained in $50 \mathrm{~mL}$ of wheat bran-agar medium (40 g of wheat bran, $20 \mathrm{~g}$ agar, $1000 \mathrm{~mL}$ of water; the wheat bran was boiled for $1 \mathrm{~h}$ ) in $250 \mathrm{~mL}$ Erlenmeyer flasks. Cultures were kept 2 days at $22{ }^{\circ} \mathrm{C}$ and then for 10 days at room temperature $\left(25^{\circ} \mathrm{C}\right)$ under fluorescent light. Conidia were extracted from each flask with sterile distilled water, washed with Tween 20 suspension ( 1 drop in $100 \mathrm{~mL}$ of water) and filtered with sterile gauze (methodology used by the Instituto Nacional de Tecnología Agropecuaria Marcos Juárez, INTA) (Galich, 1997). Three plants were planted per pot with four replicates per treatment. Inoculation was performed at early anthesis, into a central spikelet of the spike, using $20 \mu \mathrm{L}$ of inoculum at a concentration of $1 \times 10^{5}$ conidia/mL (Kang et al., 2008). The control plants were inoculated with distilled water. A growth chamber was used to incubate the plants at $90 \%$ relative humidity and $20^{\circ} \mathrm{C}$ for $72 \mathrm{~h}$ after inoculation, before taking them to the greenhouse. The aggressiveness was estimated according to the data of disease severity (DS), which was evaluated on 12 total spikes per treatment, at 6,14 and 21 days after inoculation and expressed at the percentage of symptomatic spikelets per spike (Mesterházy et al., 2005). At maturity the spikes of each replicate were harvested and threshed separately for grain weight measurement in order to calculate the parameters thousand grains weight (TGW) and relative yield reduction, considering the weight of controls as $100 \%$ (Chrpova et al., 2013). Statistical analysis was performed using a mixed model analysis of variance (ANOVA; $p=0.05$, InfoStat version 2015).

\section{Result and discussion}

\subsection{Phenotypic diversity of F. graminearum local isolates}

We here explored the global phenotype of 34 well-identified $F$. graminearum isolates obtained from wheat samples recovered from different geographic location of Argentina by FTIR spectroscopy. As a phenotypic approach, IR spectroscopy gives information of the whole cell composition and reflects the biochemical changes induced by alterations in cultivation conditions such as the type of culture medium used, and temperature and time of incubation, among other environmental factors (Bosch et al., 2006; Grunert et al., 2013; van der Mei et al., 1996; Büchl et al., 2008). Several studies have applied ATR-FTIR technique (Salman et al., 2010, 2011, 2012) or the Transition/Absorbance approaches, using lyophilized mycelium, milled with $\mathrm{KBr}$ into powder and pressed to pellets (Nie et al., 2007a,b). In this work we applied the simple FTIR dried film technology, which has widely been used for identification of bacteria and yeasts, and not yet applied to the analysis of filamentous fungi (Bosch et al., 2006; Fischer et al., 2006; Naumann, 2000).

In order to study the phenotypic heterogeneity or the diversity of $F$. graminearum local isolates a sampling protocol was first optimized to guarantee high reproducibility levels among technical and biological replicates. A significant reduction in the variance among them was achieved working with homogenous fungal suspensions obtained after 
A Spectral distance

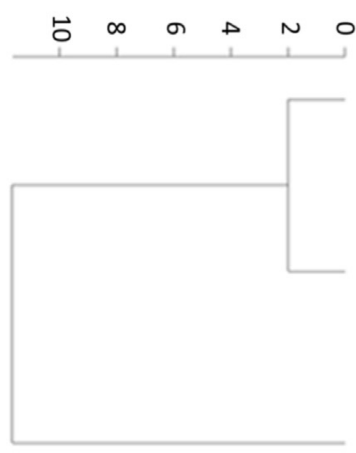

B Spectral distance
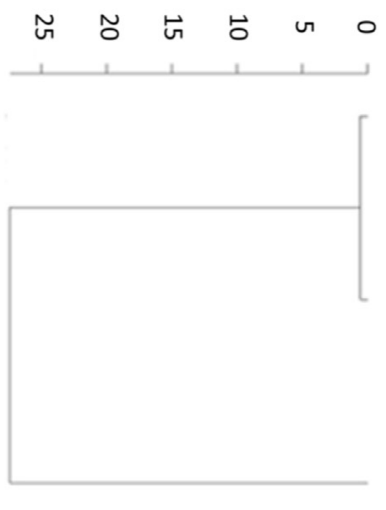

C Spectral distance

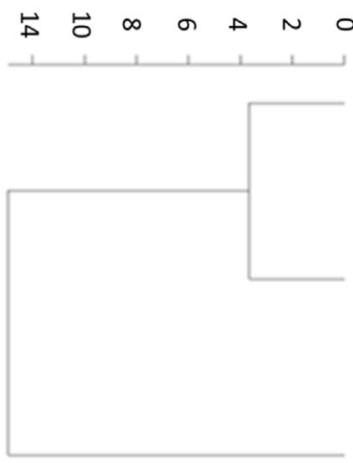

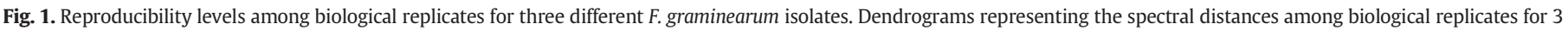

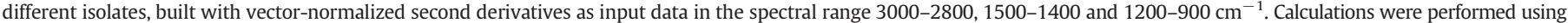

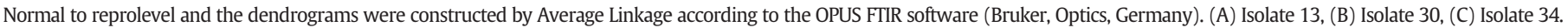

culturing in commercial PDB for 3 days and sonicating the fungal suspension as indicated in Methods.

The variability or reproducibility levels obtained among biological replicates in the whole population varied from $\mathrm{D}=10.1 \pm 3.15$ to a maximum value of $\mathrm{D}=25.2 \pm 11.85$ (Fig. 1 ). Taking into account this $D$ value two F. graminearum isolates were considered as indistinguishable by FTIR spectroscopy when $D_{1200-900}$ values calculated with their replicates were $<40$. Isolates with spectral distances lower than the cut-off number of $\mathrm{D}=40$ were assigned to the same phenotype or spectral type.

The FTIR absorption spectra of $F$. graminearum local isolates investigated in this study, showed an overall spectral feature similar to those previously reported for this species (Fig. 2) (Nie et al., 2007a; Salman et al., 2012). Spectra were dominated by a large absorption band at $1200-900 \mathrm{~cm}^{-1}$, the so-called window $4\left(\mathrm{~W}_{4}\right)$, mainly attributed to carbohydrate vibrations (Naumann, 2000). The chitin band, which is specific to fungi, was detected at $1151 \mathrm{~cm}^{-1}$ and $1076 \mathrm{~cm}^{-1}$ due to its C $-\mathrm{O}$ and $\mathrm{C}-\mathrm{C}$ stretching vibrations (Nie et al., 2007a; Salman et al., 2012), and the glycogen $\mathrm{C}-\mathrm{O}$ stretching vibrations were detected at the band $1028 \mathrm{~cm}^{-1}$ (Naumann, 2000). The infrared spectra associated with the fungal protein absorptions exhibited the typical amide I and amide II bands at $1640 \mathrm{~cm}^{-1}$ and $1546 \mathrm{~cm}^{-1}$, respectively, with relatively low intensity as previously observed for Fusarium genus by Nie et al. (2007a) and Salman et al. (2011). The main spectral features in the high wavenumber region $\mathrm{W}_{1}$ (between 2800 and $3000 \mathrm{~cm}^{-1}$ ), were the bands detected at 2922 and $2853 \mathrm{~cm}^{-1}$, assigned to the anti-

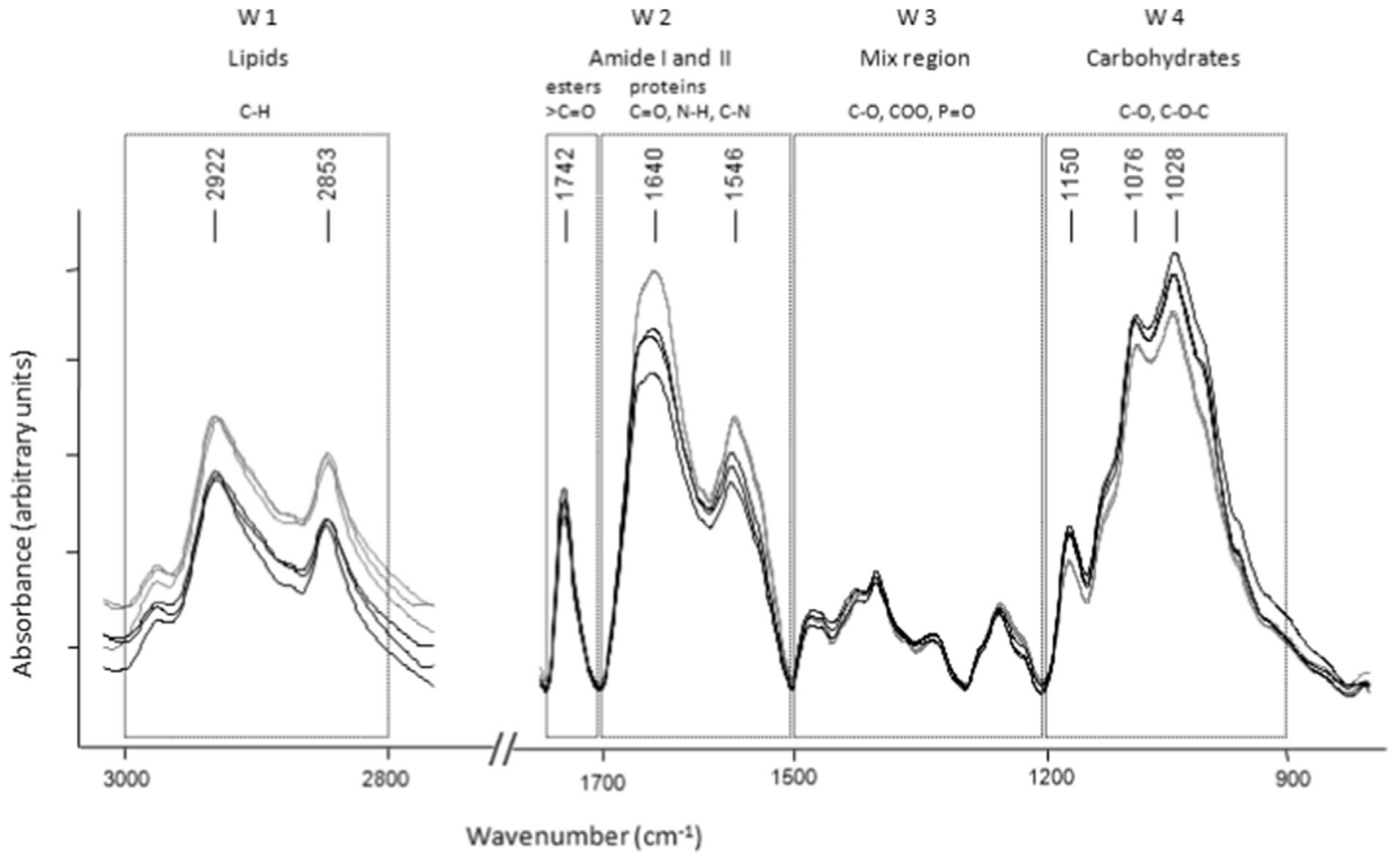

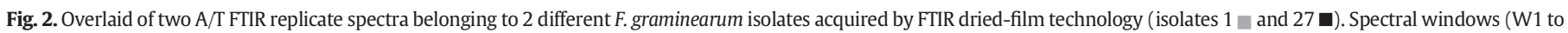
W4), and main band assignments are indicated. 
symmetric and symmetric stretching vibrations of $>\mathrm{CH}_{2}$ (Naumann, 2000). Moreover, there was a typical lipid band observed at $1742 \mathrm{~cm}^{-1}$ due to $>\mathrm{C}=\mathrm{O}$ stretching vibration of ester groups (included in Amide I at $\mathrm{W}_{2}$ window) which derives mainly from phospholipid absorbance (Naumann, 2000). In accordance with previously published results (Salman et al., 2011) spectra of the majority of local Fusarium isolates exhibited a relative increase in the intensity of the bands associated with lipids ( $>\mathrm{C}=\mathrm{O}$ assigned to esters at $1742 \mathrm{~cm}^{-1}$ ), with respect to the bands of Amide I and Amide II. These spectral features are described as distinctive for the genus Fusarium compared to other genera such as Rhizoctonia, Colletotrichum and Verticillium with greater predominance of Amide I and II against the $>C=0$ of ester (Salman et al., 2010).

We applied the spectral second derivatives as input data in an unsupervised cluster analysis to assess the phenotypic heterogeneity among the F. graminearum local isolates (Fig. 3). Taking into account the maximum value of the variance obtained for biological replicates of the individual isolates ( $D<40$ ), a cut-off line was drawn at level of fusion of 200 (heterogeneity $=200$ ) which produced a discrimination of the isolates into two main clusters (A and B, indicated by a line in Fig. 3). Taking into consideration that the spectra which grouped with a heterogeneity

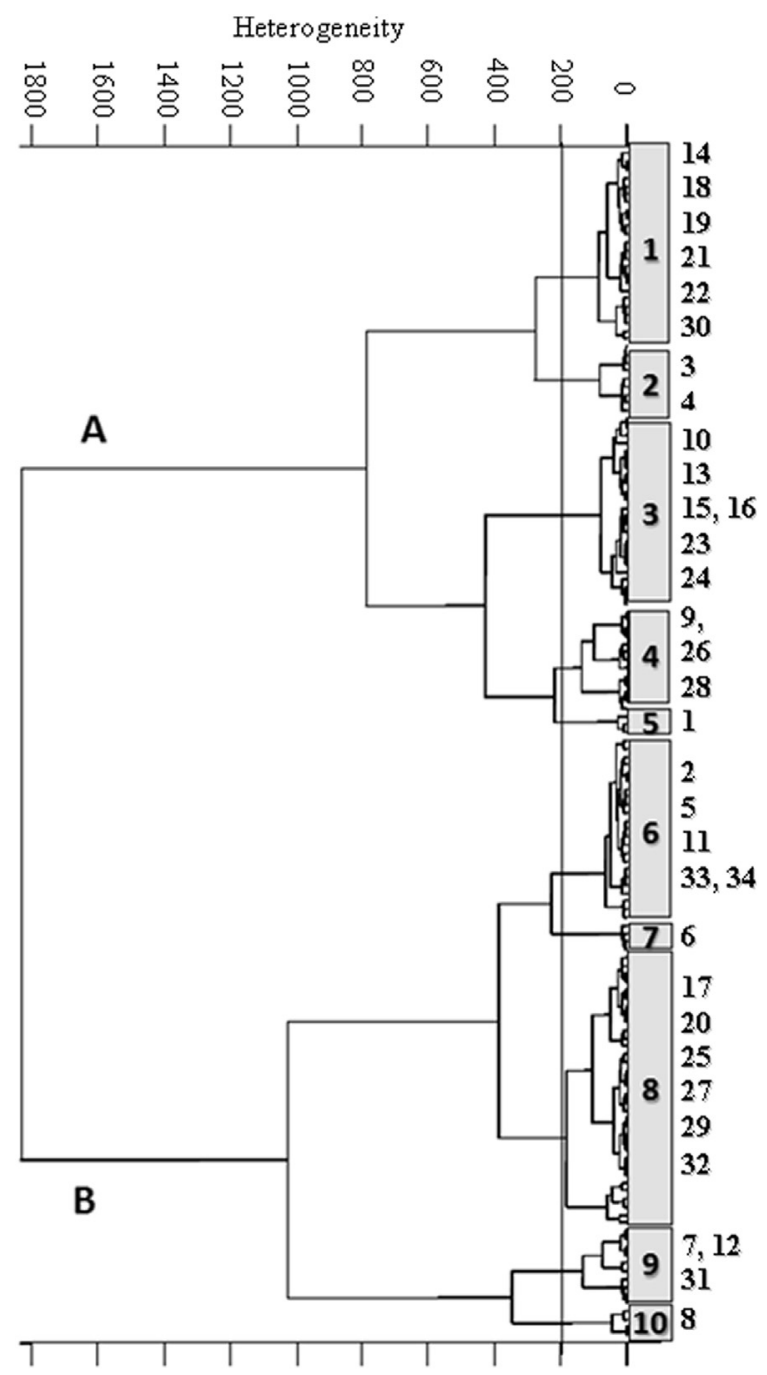

Fig. 3. Phenotypic diversity among $34 \mathrm{~F}$. graminearum isolates based on A/T FTIR spectra. The dendrogram was obtained using vector-normalized second derivatives (9-point Savitzky-Golay filter). Spectral distances were calculated with Scaling to first range in the following spectral windows: $3000-2800 \mathrm{~cm}^{-1}, 1800-1700 \mathrm{~cm}^{-1}$, and 1250 $750 \mathrm{~cm}^{-1}$, and dendrograms were obtained using Ward's algorithm according to the OPUS software (Bruker Optics, Germany). value less than the cut-off value were assigned to the same spectral phenotype, 10 spectral phenotypes were found among which 3 were represented by only one isolate (isolates 1,6 and 8 ). These findings indicated a significant phenotypic variance among isolates. These results are in agreement with previous research performed by our and other groups working with $F$. graminearum isolates recovered from Argentina, in which a high diversity in mycotoxin producing capability was detected (Alvarez et al., 2011; Ortega et al., 2016; Ramírez et al., 2007). These results together may be indicating that the phenotypic diversity encountered could be one of the strategies acquired by this pathogen to adjust to the changing environmental conditions, being therefore potentially responsible for the periodical emergence of this population in our region.

\subsection{F. graminearum aggressiveness}

In order to determine if there was any association between the fungal FTIR phenotype and fungal aggressiveness parameters, the latter were assessed on susceptible wheat inoculated independently with 9 isolates selected as indicated in Methods. The aggressiveness of the isolates estimated by DS \% during plant growth showed disease progression over time, reaching stable values toward the end of the assessment period. All isolates here assayed were able to infect and colonize wheat seedlings, meaning that all of the inoculated spikes showed symptoms of the disease, observed for its white colour and dryness. However, as previously reported in other studies carried out with $F$. graminearum populations (Aamot et al., 2015; Talas et al., 2012), significant differences in DS \% values were detected. As indicated in Table 1, a significant variance among the estimated values of aggressiveness according to DS \% was found. Considering the evaluation of this assay at 21 days after inoculation, the aggressiveness of the isolates here studied ranged from a minimum of $16.29 \%$ for isolate number 1 to a maximum of $100 \%$ for isolates number 14 and 32 . Once the spikes were harvested and threshed, the values of TGW and yield reduction were obtained from weighing the grains, showing variability ranges from $40 \mathrm{~g}$ (isolate 1) to $5 \mathrm{~g}$ (isolate 6 ) and from $20 \%$ (isolate 1 ) to $86 \%$ (isolate 6 ), respectively (Table 1 ). As it was expected, these analyzed variables also showed high variability among isolates compared to the control plants, with significant statistical differences. Likewise, in another study performed with local $F$. graminearum isolates on aggressiveness analyzed by wheat spike colonization and mycotoxin production, a high variability of responses among isolates was also encountered (Malbrán et al., 2012; Malbrán et al., 2014). Although the association between disease severity and weight loss has been reported to be controversial, (Alvarez et al., 2010; Brennan et al., 2005), our results showed a direct correlation, which is in agreement with Lemmens et al. (2004) and Mentewab et al. (2000).

Table 1

Aggressiveness of different Fusarium graminearum isolates on wheat measured by disease severity progression percentage along time (DS \%), thousand grains weight (TGW), and yield reduction percentage.

\begin{tabular}{|c|c|c|c|c|c|c|}
\hline \multirow[t]{2}{*}{ Isolates } & \multirow{2}{*}{$\begin{array}{l}\text { FTIR } \\
\text { phenotype }\end{array}$} & \multicolumn{3}{|l|}{ DS (\%)* } & \multirow[t]{2}{*}{ TGW(g) } & \multirow{2}{*}{$\begin{array}{l}\text { Yield reduction } \\
(\%)\end{array}$} \\
\hline & & $\mathrm{T} 1$ & $\mathrm{~T} 2$ & T3 & & \\
\hline 1 & A5 & $9,11^{\text {bcd }}$ & $12,42^{\text {ef }}$ & $16,29^{\mathrm{e}}$ & $40^{\mathrm{b}}$ & 20 \\
\hline 6 & B7 & $18,71^{\mathrm{a}}$ & $86,76^{\mathrm{a}}$ & $98,96^{\mathrm{ab}}$ & $5^{f}$ & 89 \\
\hline 13 & A3 & $11,59^{b}$ & $50,31^{d}$ & $79,80^{\text {cd }}$ & $17^{\mathrm{cd}}$ & 67 \\
\hline 14 & $\mathrm{~A} 1$ & $9,62^{\text {bcd }}$ & $67,72^{\mathrm{bc}}$ & $100^{\mathrm{a}}$ & $8^{e}$ & 82 \\
\hline 18 & $\mathrm{~A} 1$ & $7,81^{\mathrm{cd}}$ & $47,66^{d}$ & $99,12^{\mathrm{ab}}$ & $10^{\text {de }}$ & 79 \\
\hline 26 & A4 & $9,66^{\mathrm{bcd}}$ & $76,58^{\mathrm{ab}}$ & $99,01^{\mathrm{ab}}$ & $7^{e}$ & 84 \\
\hline 27 & B8 & $10,81^{\mathrm{bc}}$ & $59,28^{\text {cd }}$ & $87,21^{\text {bc }}$ & $10^{\mathrm{e}}$ & 78 \\
\hline 30 & A1 & $7,62^{\mathrm{cd}}$ & $25,01^{\mathrm{e}}$ & $68,57^{d}$ & $24^{\mathrm{c}}$ & 53 \\
\hline 32 & B8 & $12,16^{\mathrm{b}}$ & $86,51^{a}$ & $100^{\mathrm{a}}$ & $6^{\text {ef }}$ & 86 \\
\hline
\end{tabular}

${ }^{*} \mathrm{~T} 1, \mathrm{~T} 2$ and T3 correspond to disease severity (DS) evaluation after 6, 14 and 21 days of inoculation respectively. ${ }^{\mathrm{a}, \mathrm{b}, \mathrm{c}, \mathrm{d}, \mathrm{e}, \mathrm{f}}$ different letters means significant differences. 
Table 2

Semi-quantitative values of lipid content for different Fusarium graminearum isolates measured by FTIR spectroscopy.

\begin{tabular}{lll}
\hline Isolates & Band Area at $2853 \mathrm{~cm}^{-1 *}$ & Band Area at $1742 \mathrm{~cm}^{-1 * *}$ \\
\hline 1 & $0.023^{\mathrm{e}}$ & $0.26^{\mathrm{d}}$ \\
6 & $0.063^{\mathrm{b}}$ & $0.37^{\mathrm{b}}$ \\
13 & $0.048^{\mathrm{cd}}$ & $0.32^{\mathrm{c}}$ \\
14 & $0.054^{\mathrm{c}}$ & $0.33^{\mathrm{bc}}$ \\
18 & $0.054^{\mathrm{c}}$ & $0.34^{\mathrm{bc}}$ \\
26 & $0.055^{\mathrm{bc}}$ & $0.35^{\mathrm{bc}}$ \\
27 & $0.055^{\mathrm{bc}}$ & $0.35^{\mathrm{bc}}$ \\
30 & $0.042^{\mathrm{d}}$ & $0.33^{\mathrm{bc}}$ \\
32 & $0.084^{\mathrm{a}}$ & $0.43^{\mathrm{a}}$ \\
\hline
\end{tabular}

a,b,c,d,e different letters means significant differences.

* Band assigned to lipids ( $\mathrm{C}-\mathrm{H}$ symmetric stretching of $>\mathrm{CH} 2$ in fatty acids).

** Band assigned to lipids (to $>\mathrm{C}=\mathrm{O}$ stretching vibration of ester groups).

\subsection{Spectral spectroscopic markers associated with aggressiveness}

It is interesting to note that among the assessed fungal population, the more aggressive isolates as measured either by DS \% or yield reduction \%, were included in cluster B of the FTIR phenotype characterization (isolates 6 and 32), while the less aggressive ones were grouped in cluster A (isolates 1 and 30) (Fig. 3, Table 1). As the fungal phenotypic diversity is studied in the whole spectral range (4000 to $\left.650 \mathrm{~cm}^{-1}\right)$, we decided to search for particular

spectral markers related to aggressiveness. Interestingly, we found that spectra of the more aggressive isolates presented a significant increase in absorption intensities at the lipid regions $(\mathrm{C}-\mathrm{H}$ stretching modes associated to in $\mathrm{CH}_{2}$ and $\mathrm{CH}_{3}$, and $\mathrm{C}=\mathrm{O}$ and $\mathrm{C}-\mathrm{O}$ stretching modes associated to esters in lipids). The relative lipid content of the isolates was then estimated through the band areas at $2853 \mathrm{~cm}^{-1}$ and at $1742 \mathrm{~cm}^{-1}$ in vector normalized spectra. The result presented in Table 2 confirmed that there was a relative association between the values of the areas and the values of aggressiveness measured by both DS \% and yield reduction \%. To better visualize the correlation between lipid content and aggressiveness we performed a principal component analysis (PCA), an unsupervised multivariate statistical method using the second derivatives vector normalized spectra of three biological replicates for each isolate considering not only the band areas at 2853 and $1735 \mathrm{~cm}^{-1}$, but the three spectral windows associated to lipid content: spectral range of $3000-2800 \mathrm{~cm}^{-1}$ ( $>\mathrm{C}-\mathrm{H}$ stretching modes in lipids), $1765-1707 \mathrm{~cm}^{-1}$ ( $>\mathrm{C}=\mathrm{O}$ in esters) and $1474-900 \mathrm{~cm}^{-1}$ ( $-\mathrm{C}-\mathrm{O}$ in esters). The Score-plot for PC2 and PC4 at these particular regions revealed discrimination among spectral data according to aggressiveness levels without any previous classification procedure. As shown in Fig. 4, the almost non aggressive isolate (isolate 1 ) clearly clustered separately from those characterized by low (isolates 30 and 13), medium (isolates 14, 18, 26 and 27) and high (isolates 6 and 32) aggressiveness values. This interesting association between lipid content and aggressiveness might be related to previously reported results obtained for Fusarium verticillioides where tricarballylic ester formation was demonstrated to be important during biosynthesis of fumonisin mycotoxin ( $\mathrm{Li}$ et al., 2013). Furthermore, it is widely recognized that lipids play vital roles in numerous physiological processes in living organisms, which include those related to the interaction between hosts and pathogens. There is evidence that certain lipids such as endogenously-produced fungal oxylipins, metabolites derived from lipid peroxidation, are known for their roles in carrying out pathogenic strategies to successfully colonize their host, reproduce, and synthesize toxins (Christensen and Kolomiets, 2011; Borrego and Kolomiets, 2012; Walley et al., 2013). In conclusion, FTIR dry film technology in combination with simple multivariate analyses represent valuable tools to study the phenotypic variability among local $F$. graminearum isolates and allowed us to find an interesting association between lipid content and aggressiveness in $F$. graminearum s.s isolates. These results may be of interest for the novel studies in the area of lipid-mediated signal communication between

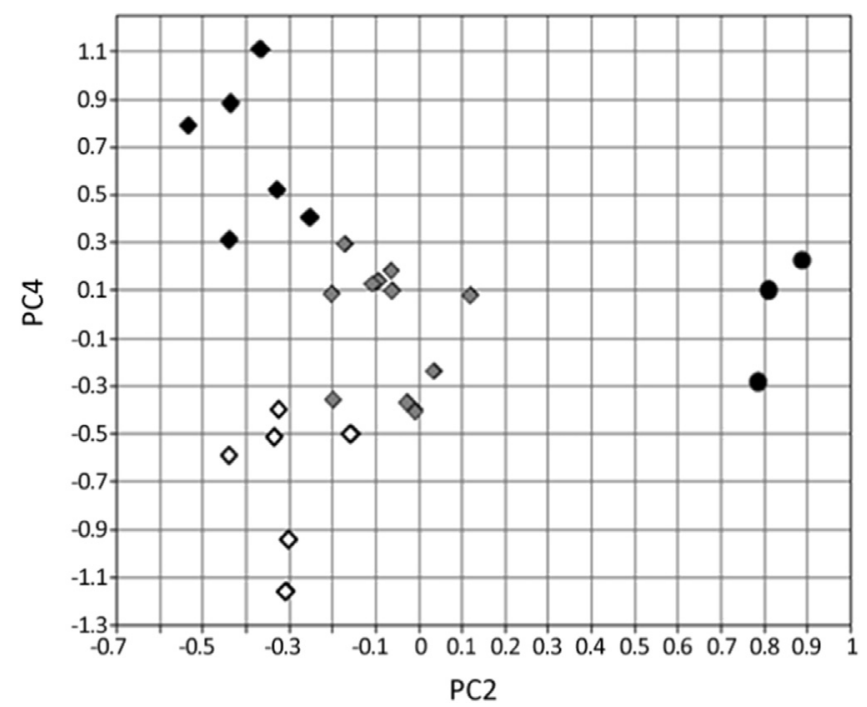

Fig. 4. PCA Score-plot based on FTIR regions assigned to lipids for $F$. graminearum isolates with different aggressiveness levels: almost not aggressive (isolate $1 \bullet$ ), low aggressiveness (isolates 30 and $13 \diamond$ ), medium aggressiveness (isolates 14, 18, 26 and $27 \diamond$ ) and high aggressiveness (isolates 6 and $32 \diamond$ ). PCA was carried out with vectornormalized second derivative spectra of three independent replicates of each isolate in the spectral range of $3000-2800 \mathrm{~cm}^{-1}, 1765-1707 \mathrm{~cm}^{-1}$ and $1474-900 \mathrm{~cm}^{-1}$.

fungi and plants which is a new and fast growing field of study relative to the interactions between organisms.

\section{Acknowledgments}

We thank Consejo Nacional de Investigaciones Científicas y Tecnológica (Grant PIP 0925) for financial support. Alejandra Bosch is a CIC PBA researcher.

\section{References}

Aamot, H.U., Ward, T.J., Brodal, G., Vralstad, T., Larsen, G.B., Klemsdal, S.S., Elameen, A., Uhlig, S., Hofgaard, I.S., 2015. Genetic and phenotypic diversity within the Fusarium graminearum species complex in Norway. Eur. J. Plant Pathol. 1-19.

Alvarez, C.L., Somma, S., Moretti, A., Fernández Pinto, V., 2010. Aggressiveness of Fusarium graminearum sensu stricto isolates in wheat kernels in Argentina. J. Phytopathol. 158, 173-181.

Alvarez, C.L., Somma, S., Proctor, R.H., Stea, G., Mulè, G., Logrieco, A.F., Fernández Pinto, V., Moretti, A., 2011. Genetic diversity in Fusarium graminearum from a major wheatproducing region of Argentina. Toxins 3, 1294-1309.

Astolfi, P. Reynoso, M.M., Ramírez, M.L., Chulze, S.N., Alves, T.C.A., Tessmann, D.J., Del Ponte, E.M., 2012. Genetic population structure and trichothecene genotypes of $\mathrm{Fu}$ sarium graminearum isolated from wheat in southern Brazil. Plant Pathol. 61, 289-295.

Bolsa de Comercio de Rosario, 2014. Publicaciones: Informativo Semanal ( $\left.N^{\circ} 1687\right)$. Argentina y su posicionamiento en el mercado mundial de granos, aceites y subproductos Available at. http://www.bcr.com.ar/Publicaciones/Informativo\% 20semanal/bcr2014_12_05.pdf> (accessed 15.04.15).

Borrego, E.J., Kolomiets, M.V., 2012. Lipid-mediated signaling between fungi and plants. In: Witzany, G. (Ed.), Biocommunications of Fungi. Springer, Netherlands, pp. 249-260.

Bosch, A., Golowczyc, M.A., Abraham, A., Garrote, G., De Antoni, G., Yantorno, O., 2006. Rapid discrimination of lactobacilli isolated from kefir grains by FTIR spectroscopy. Int. J. Food Microbiol. 111, 280-287.

Bosch, A., Miñán, A., Vescina, C., Degrossi, J., Gatti, B., Montanaro, P., Naumann, D. 2008. Fourier transform infrared spectroscopy for rapid identification of nonfermenting gram-negative bacteria isolated from sputum samples from cystic fibrosis patients. J. Clin. Microbiol. 46 (8), 2535-2546.

Brennan, J.M., Egan, D., Cooke, B.M., Doohan, F.M., 2005. Effect of temperature on head blight of wheat caused by Fusarium culmorum and F. graminearum. Plant Pathol. 54, 156-160.

Büchl, N.R., Wenning, M., Seiler, H., Mietke-Hofmann, H., Scherer, S., 2008. Reliable identification of closely related Issatchenkia and Pichia species using artificial neural network analysis of Fourier-transform infrared spectra. Yeast 25 (11), 787-798.

Burgess, L.W., Summerell, B.A., Bullock, S., Gott, K.P., Backhouuse, D., 1994. Laboratory Manual for Fusarium Research. third ed. University of Sydney, Sydney.

Carter, J.P., Rezanoor, H.N., Holden, D., Desjardins, A.E., Plattner, R.D., Nicholson, P., 2002. Variation in pathogenicity associated with the genetic diversity of Fusarium graminearum. Eur. J. Plant Pathol. 108, 573-583. 
Castañares, E., Ramírez Albuquerque, D., Dinolfo, M.I., Fernández Pinto, V., Patriarca, A., Stenglein, S.A., 2014. Trichothecene genotypes and production profiles of Fusarium graminearum isolates obtained from barley cultivated in Argentina. Int. J. Food Microbiol. 179, 57-63.

Christensen, S.A., Kolomiets, M.V., 2011. The lipid language of plant-fungal interactions. Fungal Genet. Biol. 48 (1), 4-14.

Chrpova, J., ŠíP, V., Štockova, L., Stehno, Z., Capouchova, I., 2013. Evaluation of resistance to fusarium head blight in spring wheat genotypes belonging to various Triticum species. Czech J. Genet. Plant Breed. 49 (4), 149-156.

Cumagun, C.J.R., Miedaner, T., 2004. Segregation for aggressiveness and deoxynivalenol production of a population of Gibberella zeae causing head blight of wheat European. J. Plant Pathol. 110, 789-799.

Engle, J.S., Madden, L.V., Lipps, P.E., 2003. Evaluation of inoculation methods to determine resistance reactions of wheat to Fusarium graminearum. Plant Dis. 87 (12), 1530-1535.

Fischer, G., Braun, S., Thissen, R., Dott, W., 2006. FTIR spectroscopy as a tool for rapid identification and intra- species characterization of airborne filamentous fungi. J. Microbiol. Methods 64 (1), 63-77.

Galich, M.T., 1997. Fusarium head blight in Argentina. In: Duvin, H.J., Gilchrist, R., Reeves, J., McNab, A. (Eds.), Fusarium Head Scab: Global Status and Future Prospects. Centro Internacional de Mejoramiento de Maíz y Trigo, México, pp. 19-28.

Gerlach, W., Nirenberg, H., 1982. The genus Fusarium - A pictorial atlas. Mitteilungen aus der Biologischen Bundesanstalt fur Land-und Forstwirtschaft Berlin-Dahlem 209, $1-406$.

Goswami, R.S., Kistler, H.C., 2004. Heading for disaster: Fusarium graminearum on cereal crops. Mol. Plant Pathol. 5 (6), 515-525.

Grunert, T., Wenning, M., Barbagelata, M.S., Fricker, M., Sordelli, D.O., Buzzola, F.R., EhlingSchulz, M., 2013. Rapid and reliable identification of Staphylococcus aureus capsular serotypes by means of artificial neural network-assisted Fourier transform infrared spectroscopy. J. Clin. Microbiol. 51, 2261-2266.

Helm, D., Labischinsky, H., Schallehn, G., Naumann, D., 1991. Classificaton and identification of bacteria by Fourier-transform infrared spectroscopy. J. Gen. Microbiol. 137, 69-79.

Helm, D., Naumann, D., 1995. Identification of some bacterial cell components by FTIR spectroscopy. FEMS Microbiol. Lett. 126, 75-80.

Hossain, M.Z., Goto, T., 2014. Near- and mid-infrared spectroscopy as efficient tools for detection of fungal and mycotoxin contamination in agricultural commodities. World Mycotoxin J. 7 (4), 508-515.

Kang, Z., Buchenauer, H., Huang, L., Han, Q., Zhang, H., 2008. Cytological and immunocytochemical studies on responses of wheat spikes of the resistant Chinese cv. Sumai 3 and the susceptible cv. Xiaoyan 22 to infection by Fusarium graminearum. Eur. J. Plant Pathol. 120, 383-396.

Kikot, G., Moschini, R., Consolo, F., Rojo, R., Hours, R., Salerno, G., Gasoni, L., Arambarri, M.A., Alconada, T.M., 2011. Occurrence of Fusarium graminearum from wheat in relation to climatic models in Argentina Pampas Region. Mycopathologia 171, 139-149.

Kohler, A., Böcker, U., Shapaval, V., Forsmark, A., Andersson, M., Warringer, J., Martens, H., Omholt, S.W., Blomberg, A., 2015. High-throughput biochemical fingerprinting of Saccharomyces cerevisiae by Fourier transform infrared spectroscopy. PLoS One 10 (2), e0118052.

Lecellier, A., Gaydou, V., Mounier, J. Hermet, A., Castrec, L., Barbier, G., Ablain, W., Manfait, M., Toubas, D., Sockalingum, G.D., 2015. Implementation of an FTIR spectral library of 486 filamentous fungi strains for rapid identification of molds. Food Microbiol. 45, 126-134.

Lemmens, M., Haim, K., Lew, H., Ruckenbauer, P., 2004. The effect of nitrogen fertiliser on Fusarium head blight development and deoxynivalenol contamination in wheat. J. Phytopathol. 152, 1-8.

Leslie, J.F., Anderson, L.L., Bowden, R.L., Lee, Y.-W., 2007. Inter- and intra-specific genetic variation in Fusarium. Int. J. Food Microbiol. 119 (1), 25-32.

Leslie, J.F., Summerell, B.A., 2006. The Fusarium Laboratory Manual. first ed. 110(4). Ames: Backwell, pp. 573-585.

Levasseur, C., Pinson-Gadais, L., Kleiber, D., Surel, O., 2010. Near infrared spectroscopy used as a support to the diagnostic of Fusarium species. Revue de Médecine Véterinaire 161 (10), 438-444.

Li, Y., Lou, L., Cerny, R.L., Butchko, R.A., Proctor, R.H., Shen, Y., Du, L., 2013. Tricarballylic ester formation during biosynthesis of fumonisin mycotoxins in Fusarium verticillioides. Mycology 4 (4), 179-186.

Malbrán, I., Mourelos, C.A., Girotti, J.R., Aulicino, M.B., Balatti, P.A., Lori, G.A., 2012. Aggressiveness variation of Fusarium graminearum isolates from Argentina following point inoculation of field grown wheat spikes. Crop. Prot. 42, 234-243.

Malbrán, I., Mourelos, C.A., Girotti, J.R., Balatti, P.A., Lori, G.A., 2014. Toxigenic capacity and trichothecene production by Fusarium graminearum isolates from Argentina and their relationship with aggressiveness and fungal expansion in the wheat spike. Phytopathology 104, 357-364.

Matny, O.N., 2015. Fusarium head blight and crown rot on Wheat \& Barley: losses and health risks. Advances in Plants \& Agriculture Research 2 (1), 00039.
Mariey, L., Signolle, J.P., Amiel, C., Travert, J., 2001. Discrimination, classification, identification of microorganisms using FTIR spectroscopy and chemometrics. Vib. Spectrosc. 26 (2), 151-159.

Mentewab, A., Rezanoor, H.N., Gosman, N., Worland, A.J., Nicholson, P., 2000. Chromosomal location of Fusarium head blight resistance genes and analysis of the relationship between resistance to head blight and brown foot rot. Plant Breed. 119, 15-20.

Mesterházy, A., Barto, T., Kaszonyi, G., Varga, M., Toth, B., Varga, J., 2005. Common resistance to different Fusarium spp. causing fusarium head blight in wheat. Eur. J. Plant Pathol. 112, 267-281.

Naumann, D., 2000. Infrared spectroscopy in microbiology. In: Meyers, R.A. (Ed.), Encyclopedia of Analytical Chemistry: Applications, Theory, and Instrumentation. John Wiley \& Sons Ltd., Chichester, United Kingdom.

Nelson, P.E., Dignani, M.C., Anaissie, E.J., 1994. Taxonomy, biology and clinical aspects of Fusarium species. Clin. Microbiol. Rev. 74 (4), 479-504.

Nicholson, P., Simpson, D.R., Weston, G., Rezanoor, H.N., Lees, A.K., Parry, D.W., Joyce, D., 1998. Detection and quantification of Fusarium culmorum and Fusarium graminearum in cereals using PCR assay. Physiol. Mol. Plant Pathol. 53, 17-37.

Nie, M., Luo, J., Xiao, M., Chen, J., Bao, K., Zhang, W., Chen, J., Li, B., 2007a. Structural differences between Fusarium strains investigated by FTIR spectroscopy. Biochemical 72, 61-67.

Nie, M., Zhang, W.Q., Xiao, M., Luo, J.L., Bao, K., Chen, J.K., Li, B., 2007b. FTIR spectroscopy and artificial neural network identification of Fusarium species. J. Phytopathol. 115, 364-367.

Ortega, L.M., Dinolfo, M.I., Astoreca, A.L., Alberione, E.J., Stenglein, S.A., Alconada, T.M. 2016. Molecular and mycotoxin characterization of Fusarium graminearum isolates obtained from wheat at a single field in Argentina. Mycol. Prog. 15 (1), 1-8.

Pestka, J.J., 2007. Deoxynivalenol: toxicity, mechanisms and animal health risks. Anim. Feed Sci. Technol. 137, 283-298.

Ramírez, M.L., Reynoso, M.M., Farnochi, M.C., Torres, A.M., Leslie, J.F., Chulze, S.N., 2007. Population genetic structure of Gibberella zeae isolated from wheat in Argentina. Food Addit. Contam. 24, 1115-1120.

Rebuffo, C.A., Schmitt, J., Wenning, M., von Stetten, F., Scherer, S., 2006. Reliable and rapid identification of Listeria monocytogenes and Listeria species by artificial neural network-based Fourier Transform infrared spectroscopy. Appl. Environ. Microbiol. 994-1000.

Reynoso, M.M., Ramirez, M.L., Torres, A., Chulze, S., 2011. Trichothecene genotypes and chemotypes in Fusarium graminearum strains isolated from wheat in Argentina. Int. J. Food Microbiol. 145, 444-448.

Salman, A., Tsror, L., Pomerantz, A., Lapidet, A., Morehc, R., Mordechai, S., Huleihel, M. 2011. Distinction of Fusarium oxysporum fungal isolates using FTIR-ATR spectroscopy and advanced statistical methods. Analyst 136, 988-995.

Salman, A., Tsror, L., Pomerantz, A., Morehc, R., Mordechai, S., Huleihel, M., 2010. FTIR spectroscopy for detection and identification of fungal phytopathogens. Spectroscopy 24 (3-4), 261-267.

Salman, A., Tsror, L., Pomerantz, A., Morehc, R., Mordechai, S., Huleihel, M., 2012. Identification of fungal phytopathogens using ATR-FTIR spectroscopy and advanced statistical methods. J. Biomed. Opt. 17 (1), 1-8.

Somma, S., Petruzzella, A.L., Logrieco, A.F., Meca, G., Cacciola, O.S., Moretti, A., 2014. Phylogenetic analyses of Fusarium graminearum strains from cereals in Italy, and characterisation of their molecular and chemical chemotypes. Crop Pasture Sci. 65, 52-60.

Stenglein, S.A., Balatti, P.A., 2006. Genetic diversity of Phaeoisariopsis griseola in Argentina as revealed by pathogenic and molecular markers. Physiol. Mol. Plant Pathol. 68 158-167.

Talas, F., Kalih, R., Miedaner, T., 2012. Within-field variation of Fusarium graminearum isolates for aggressiveness and deoxynivalenol production in wheat head blight. Phytopathology 102 (1), 128-134.

Umpiérrez-Failache, M., Garmendia, G., Pereyra, S., Rodríguez-Haralambides, A., Ward, V. Vero, S., 2013. Regional differences in species composition and toxigenic potential among Fusarium head blight isolates from Uruguay indicate a risk of nivalenol contamination in new wheat production areas. Int. J. Food Microbiol. 166, 135-140.

Walley, J.W., Daniel, J., Kliebenstein, D.J., Bostock, R.M., Dehesh, K., 2013. Fatty acids and early detection of pathogens. Curr. Opin. Plant Biol. 16, 520-526.

van der Lee, T., Zhang, H., van Diepeningen, A., Waalwijk, C., 2015. Biogeography of Fusarium graminearum species complex and chemotypes: a review. Food Addit. Contam. 32, 453-460.

van der Mei, H.C., Naumann, D., Busscher, H.J., 1996. Grouping of streptococcus mitis strains grown on different growth media by FT-IR. Infrared Phys. Technol. 37 (4), 561-564.

Wang, J.-H., Ndoye, M., Zhang, J.-B., Li, H.-P., Liao, Y.-C., 2011. Population structure and genetic diversity of the Fusarium graminearum species complex. Toxins 3, 1020-1037.

Wenning, M., Breitenwieser, F., Konrad, R., Huber, I., Busch, U., Scherer, S., 2014. Identification and differentiation of food-related bacteria: a comparison of FTIR spectroscopy and MALDI-TOF mass spectrometry. J. Microbiol. Methods 103, 44-52.

$\mathrm{Xu}, \mathrm{X}$., 2003. Effects of environmental conditions on the development of Fusarium ear blight. Eur. J. Plant Pathol. 109, 683-689. 